visible throagh a speculum. Carcinoma of the cervix will be accompanied by history and physical signs. Orcasionally one meets in a primigravida a condition of "high head" which is suggestive of disproportion. The commencement of the cardinal symptoms of phacenta praevia suggests this abnormality, but a careful examination must be made to confirm the diagnosis. We have had a case lately at the Rotunda where the placenta acted as a mechanical cause of delay in labour, and this was perfectly evident at the Caesarean section operation which was indicated later. It is only necessary to draw attention to this differential point in diagnosis, and to remember that occasionally the two may occur together.

Hydrocephalus must be mentioned, for the enormously scparated fontanelles may give the impression of a cervix with placenta protruding through. In addition the height of the head when felt by the abdomen may give a wrong impression. Anencephalus may simulate anything. Vasa praevia may suggest placenta praevia, but it is unimportant.

The condition which is most frequently mistaken for placenta praevia is accidental haemorrhage, and since the treatment for each of these conditions is very different, and as the treatment for the one is entirely unsuitable for the other, the importance of making a correct diagnosis is obvious. It is well at this stage to consider the various factors in making a diagnesis between the two.

(a) Parity. Placenta praevia is more common in the multiplara than in the primigravida, but it is fout in the primigravida. Accidental haemorrhage is always found in the multiparous patient.

(b) Toxaemic symptoms are nearly always present in accidental haemorrhage, and they are usually absent in placenta praevia. In spite of this assertion it is necessary to give a warning : accidental haemorrhage may occur without toxaemia, and severe toxaemia accompanied by placenta praevia may arise. During the past year a patient who was being carefully observed during her pregnancy developed albuminuria near the end. She was admitted to hospital, and efforts were made to overcome the toxaemia. The albaminuria never disappeared, and a week before term all symptoms of ptacenta praevia were present. We were dealing with a hugely fat primiparous patient with albuminuria, a one-finger cervix, and central placenta praevia. For this rare combination of circumstances there was only one treatment-Caesarean section. In this exceptional case the diagnosis was difficult. It was made withont vaginal examination, and confirmed by a vaginal examination immediately before operation.

(c) Period of pregnancy. Aceidental haemorrhage varies. Placenta praevia more commonly occurs as a premature birth.

(d) Pains are a usual accompaniment of accidental haemorrhage; they are always absent in placenta praevia.

(c) The abdomen is tense, and the presenting part is fixed in accidental haemorrhage; while in placenta praevia there is a flaccid abdomen with malpresentation or non-fixation of the presenting part.

(f) The foctus is dead in the majority of cases of accidental haemorrhage; it is alive at the commencement of labour in placenta praevia.

(g) The hacmorrthage which occurs in accidental haemorrhage is continuous and is blood-stained serum; it has been squeezed out of the uterus like the juice from an orange. The haemorrhage in placenta praevia is fresh chotted blood, which may come in gashes and varies in amount.

Finally, in discussing differential diagnosis we must refer to a type of case oocasionally encountered and already mentioned. A woman who is eight months preqnant suddenly pours blood, becomes collapsed, with imperccptible pulse and other accompanying symptoms. Does one waste time in diagnosis? No, for it is nearly certain. She is immediately given treatment for collapse, while pledgets of cotton-wool are boiled in a saucepan; these are used to stop the haemorrhage, and the absolute diagnosis is made later when the collapse symptoms have disappeared, and therefore when the patient is ready for actire treatment.

\section{Prognosis and Dangers.}

The prognosis where a case has been correctly diagnosed and treated is excellent; in fact, we feel we may borrow an apt aphorism on another subject, and say "our patient shoukd not die from placenta praevia."

There are dangers, both immediate and remote. Death from collapse following haemorrhage is possible. Death from sepsis from manipulations, low implantation, and diminished vitality must be feared. Anaemia may last for some time, and the patient should be allowed to recover thoroughly from a placenta praevia confinement before embarking on another pregnancy. Contrary to the experience of others, neither adherent placenta nor post-partum haemorrhage has been found common with our patients.

To our mind, the prognosis depends on diagnostic ability with choice and technique of treatment. Treatment does not come within the scope of this communication.

\section{SUMMaRY}

1. It is difficult to separate diagnosis from treatment.

2. Nomenclature, both with regard to period of pregnancy and situation of placenta, is considered.

3. Rigby of Notts should be given priority in making a diagnosis between placenta praevia and accidental haemorrhage.

4. A pathological condition of the endometrium is a fruitful cause of placenta pracvia. Curettage should be done before the next pregnancy.

5. The incidence of placenta praevia in 60,000 deliveries was 1 in 183, while the mortality was 1 in 17. There has been no mortality at the Rotunda Hospital in the last 55 cases.

6. Although there are others, accidental haemorrhage is the important condition to diagnose from placenta praevia. The methods of doing so are given.

7. Prophylactic submammary saline is an essential part of treatment during the diaguosis.

8. Toxaemia is not a usual accompaniment of placenta praevia; an exceptional case where it occurred is mentioned.

We shall conclude by saying that the whole payer might have been summed ul in a few words as follows: That the symptoms and diagnosis of placenta praevia might be written down-an absolutely painless clotted haemorrhage, insidious in nature, some time in the last three months of pregnancy. It seemed necessary, however, to refer to some salient points in order to remind ourselves and the world that women may be saved by a careful and exhaustive diagnosis which leads to correct treatment and a satisfactory result.

\section{LITERATURE.}

Portal: La Pratique des Accouchements, 1685

Rigby : Esary on Vterine Haemorthage. London, Jos. Johnston, 1775

Mauricenu: De lacconcliement auquel larvière faix representé io

premies on est tout-â-fait kortit devant l'enfant, 1668

Giffard: Cases in Midwifery, 1734

De Graaf: De Mulierum. Organis.

Roederer: Elementa artis obstetricae, 1759

Petit: Histoire de l'Acallémie Royale des Sciences, 1728.

Levret: L'Art des Accouchements, 1761, p. 342

Smellie : Theory and Practice of Midwifery. dentsch. Gesellsch. f. Gyn. of

Herff: Zur Lehre von der Placenta Praevia, Zeit. f. Geb. u. Gyn., 1896 Ierf : Zur Lehre

Winckels : Haudbuch der Geb., 1904, ii, 1198, 1257.

Roluma Hospital Reports.

\section{THE TREATMENT OF PLACENTA PRAEVIA.* \\ BY}

F. HAMILTON LACEY, M.D., Сн.B.,

CLINICAL LECTURER IN OBSTETRICS AND GYNAECOLOGY, VICTORI UNIVERSITY OF MANCHESTER; HONORARY SURGEON, ST. MARY'S HOSPTTALS, MANCHESTER.

In considering the treatment of placenta praevia we should immediately begin on common ground regarding the definition of this condition, as in well-known textbooks describing the three forms-central, lateral, and marginal, according to the position of the placenta in relation to the lower uterine segment-there is a difference in the nomenclature of the marginal and lateral varieties: the position of the placenta described by Fothergill as marginal is termed lateral by Fairbairn.

I have always used the term " lateral" for the condition in which the os is approached or partly covered by the placenta, and " marginal" when only the margin of the placenta extends into the lower uterine segment. It is often difficult when there is a history of slight haemorrhage at, say, the sixth or serenth month, followed by perhaps another slight haemorrhage within several weeks, to decide whether to temporize in the hope that the child may have a favourable chance, or whether to empty the uterus

* Read in a discussion in the Section of Obstetrics and Gynacologe at the Annual Meeting of the British Medical Association, Manchester 
immediately. Since the child in these cases is usually born prematurely, even when there has been no intervention, and the proportion of stillbirths is very high, the treatment adopted should be that which gives the best maternal results; if there is a history of serere haemorrhage or recurring slight haemorrhage, the uterus should be evacuated when the mother is in good condition, so that probably severe post-partum haemorrhage, sepsis, pulmonary embolism, or other complications, might be avoided. The natural inclination is to temporize when the haemorrhage is not severe, and I, like others, was inclined to do this until I had the experience in several instances of being summoned urgently to a patient whom $I$ had been watching for some time, to find her collapsed from sudden and severe hacmorrhage.

I have taken the treatment and results of 562 cases treated during the last ten years (1919 to 1928 inclusive) at St. Mary's Hospital, Manchester; if I had omitted the last year (1928) the results would have shown a much lower maternal mortality. It. is very necessary to consider a large number of cases, as in this series there was a sequence of 147 in 1925-6-7 with only one death. Of the $562,19.2$ per cent. were primiparae, and the multiparae had an average number of 4.9 children. The methods of treatment adopted were as follows.

Rupture of the Membranes.-This was carried out in 126 cases, with a maternal mortality of 3 (2.3 per cent.), and 45 per cent. of the children were stillborn. This treatment was used in the less severe cases of haemorrhage, especially when the os was slightly dilated; in the majority of these cases the placenta was marginal.

Natural Forces.-In 76 cases no active treatment was adopted, as the hacmorrhage was either slight or ceased after admission to hospital, or there were marked uterine contractions; there were two maternal deaths (2.6 per cent.); stillbirths 30 per cent. The deaths were due to phthisis and mitral disease, and not to placenta praevia.

Version.-This was performed in 273 cases, with a maternal mortality of 21 (7.6 per cent.), and 81 per cent. of the children were stillborn. External version was performed in 28 cases, with a maternal mortality of 1 (3.5 per cent.). Internal version was performed in 228 cases, with a maternal mortality of 17 (7.4 per cent.); after a leg had been brought down the iabour was allowed to terminate naturally. Internal version and immediate extraction was performed in 17 cases, with a maternal mortality of 3 ( 17.6 per cent.); one of these patients had been delivered by version before admission, and was sent into hospital on account of a ruptured uterus, which was immediately packed; she recovered.

As we see, version in one form or other was the most common form of treatment, and has in the past been most popular, as it may be carried out by anyone with moderate obstetrical knowledge and skill, but the foetal mortality is always appalling. These results show, as has so often been shown, that version with immediate extraction gives bad results - the maternal mortality in this series reaching 17.6 per cent.--since the cervix tears so readily, especially in delivering the arms and the aftercoming head, causing post-partum haemorrhage and leading to sepsis.

Brecch.-There were 21 cases of breech presentation, in which a leg was brought down and labour left to terminate naturally; in this series there were no maternal deaths.

Caesarean Section.-Classical Caesarean section was performed on 33 patients. Of these, 18 were primiparae of an average age of 27 years, and most of them were in the last two weeks of pregnancy; there were 2 deaths, giving a maternal mortality of 6 per cent.; the stillbirths were 13 per cent. One of the deaths occurred in a case complicated by contracted pelvis, and the other was a severe cardiac patient, seven months pregnant, who was too ill for a general anaesthetic, so a spinal anaesthetic was administered.

Induction.-Fifteen cases were treated by induction, either in the form of a Taylor's or Champetier de Ribes's bag or by packing. In this series there were no deaths, but the stillbirths were 70 per cent.

Vulsellum; Continuous Weight.-In 11 cases the treatment, as suggested by Willett, ${ }^{1}$ of fixing an instrument to the foetal scalp and attaching a small weight was adopted; of these the maternal mortality was nil and the stillbirths were 27 per cent.; it was found that a vulsellum with about $1 \frac{1}{2} \mathrm{lb}$. attached gave the best results, as a heavier weight produced injury to the scalp, whereas this weight did not produce any serious injury, and yet ended labour within a few hours.

TABLE I.-Showing Maternal and Foetal Mortality.

\begin{tabular}{|c|c|c|c|c|c|c|}
\hline & & & \multirow{2}{*}{$\begin{array}{l}\text { No. of } \\
\text { Cases. }\end{array}$} & \multicolumn{2}{|c|}{ Maternal Deaths. } & \multirow{2}{*}{$\begin{array}{l}\text { Stillbirths. } \\
\text { Per cent. }\end{array}$} \\
\hline & & & & No. & Per cent. & \\
\hline Membranes ruptured & $\ldots$ & $\ldots$ & 126 & 3 & 2.3 & $4 \hat{~}$ \\
\hline Natural forces & $\ldots$ & ... & 76 & 2 & 2.6 & 30 \\
\hline $\begin{array}{lll}\text { Version } & \ldots & \ldots\end{array}$ & $\ldots$ & $\ldots$ & 273 & 21 & 7.6 & 81 \\
\hline External version ... & $\cdots$ & $\ldots$ & 28 & 1 & 3.5 & - \\
\hline Internal version $\ldots$ & $\cdots$ & $\ldots$ & 228 & 17 & 7.4 & - \\
\hline Internal version and & trac & & 17 & 3 & 17.6 & - \\
\hline $\begin{array}{llll}\text { Lreech } & \ldots & \ldots & \ldots\end{array}$ & $\ldots$ & $\cdots$ & 21 & 0 & - & - \\
\hline Caesarean section $\ldots$ & $\ldots$ & $\ldots$ & 33 & 2 & 6.0 & 13 \\
\hline Inüuction $\quad \ldots \quad \ldots$ & $\ldots$ & $\ldots$ & 15 & 0 & - & 70 \\
\hline Weighted vulsellum & $\ldots$ & $\ldots$ & 11 & 0 & - & 27 \\
\hline Forcens ... $\quad \ldots$ & $\ldots$ & $\ldots$ & 7 & 0 & - & - \\
\hline
\end{tabular}

Although perfectly aware that $I$ am venturing on dangerous ground, owing to the abuse of Caesarean section in the past, yet I do think that this operation might be employed a little more frequently, especially for those at or near full term with a centrally situated placent: and the os almost closed, and in elderly primiparae; of the two deaths in this scries of 33 Caesarean sections, one occurred owing to severe cardiac complications when a spinal anaesthetic was employed, the cardiac condition being too bad for a general anaesthetic; tho maternal mortality in Caesarean section is as low as, or lower than, in other methods, such as version, and the percentage of living children is very much greater than in version.

Frey ${ }^{2}$ has given the results of Walthard's Clinic at Zürich, where for many years all cases of placenta praevia which required operative treatment were delivered by Caesarean section; in a series of 79 cases the maternal mortality was 1.2 per cent. Kolthauer ${ }^{3}$ has shown that in the Women's Clinic at Bremen, of 67 cases treated by different methods the maternal mortality was 11.9 per cent. and the child mortality 61.2 per cent.; after this series Caesarean section was used in the subsequent 29 cases, resulting in a maternal mortality of 6.9 per cent. and a child mortality of 17.3 per cent. I notice that from the reports of the Edinburgh Royal Maternity and Simpson Memorial Hospital this operation is coming more into favour and is yielding very good results.

\section{Maternal Mortality.}

Of the 562 cases, 28 terminated in the death of the mother-a mortality of 4.9 per cent.; in over 60 per cent. of these fatal cases the placenta was centrally situated; 15 per cent. had been treated at home for haemorrhage, in some cases even for weeks, so that they were in a very weak condition when admitted to hospital. This shows how important it is that every woman suffering from haemorrhage during pregnancy, however slight, should be admitted immediately to a nursing home or hospital where she can be under constant supervision.

In the fatal cases the treatment was as follows.

$$
\begin{aligned}
& \text { Version } \\
& \text { Membranes ruptured } \\
& \text { Natural forces } \\
& \begin{array}{l}
\cdots \\
\cdots \\
\cdots
\end{array} \\
& \begin{array}{lllr}
\ldots & \ldots & \ldots & 21 \\
\ldots & \ldots & \ldots & 3 \\
\ldots & \ldots & \ldots & 2 \\
\ldots & \ldots & \ldots & 2
\end{array} \\
& \text { TABle II.-Causes of Dcath. } \\
& \begin{array}{lll}
\ldots & \ldots & 6 \\
\ldots & \ldots & 5
\end{array}
\end{aligned}
$$

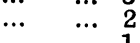

$$
\begin{aligned}
& \begin{array}{ll}
\ldots & 1 \\
\ldots & 1
\end{array}
\end{aligned}
$$
by the ante-partum haemorrhage. 
In the Rotunda Hospital Reports ${ }^{4}$ 1918-27 (nine years) there were 124 cases, with a mortality of 7.3 per cent. Hitschmann ${ }^{5}$ gives the following figures: Döderlein 19 per cent., Kernig 18.2 per cent., Mende 15 per cent., Lefebre 19.3 per cent., and Charlaies 15.5 per cent.

\section{Summary.}

1. Placenta praevia is one of the most dangerous complications of childbirth.

2. Haemory hage is a prominent feature, and often there is a history of previous recurring haemorrhage.

3. Since haemorrhage, shock, and sepsis are the commonest eaves of death, it is better to emipty the nterus soon when the patient is in good condition, rather than attempt to temporize.

4. Central placenta praevia has the greatest maternal and foetal mortality, and there is scope for a slightly higher proportion of Caesarean sections in this type of case, especially when the foetus is alive and near full term.

5. Of the children, 75 per cent. were premature, so that the foetal mortality was high, no matter what treatment was adopted.

6. Careful ante-natal supervision shrould reduce considerably both maternal and foetal mortality.

7. Experience of Willett's treatment was limited, but it has given good resuits when used.

\section{REPRREXCES.}

1 Proce Rey. Soc. Med., Otstet. und Gynaceol. Sec., vol. 18. 2Z Zentralul. f. Bie Therapie der Placenta P'raevia, 1921.

\section{OPERATIVE TREATMENT IN TUBERCULOSIS OF THE LARGER JOINTS.*}

BY

G. R. GIRDLESTONE, M.B., F.R.C.S.,

HONORARY SURGEON, WINGTIRLD ORTHOPAEDIC FOSPITAL, OXFORD.

\section{PART I}

Scope.

Oor subject is of the utmost importance to all who have to deal with "surgical tuberculosis," and is therefore bound to raise questions of great interest to the practitioner as well as to the orthopaedic surgeon. J. appreciate rery much the honour of opening the discussion. First I sought guidance on the interpretation of the term "larger" joints, and was told that the hip, knee, ankle, shoulder, elbow, and sacro-iliac joints were inside and the spine outside the term.

Then I noted that we are limited to operations "in the treatment of tuberculosis," and I would suggest that whilo diagnostic operations are so intimately concerneà with treatment that they can rightly be reviewed in passing, operations for the correction of deformities left by tuberculosis, or operations designed to restore movemerit to fixed and soundly healed joints, must be excluded. We have today, therefore, no concern with operations other than those helpful in the treatment of unhealed tuberculosis. Surgery may be required for the complication of pyogenic infection, but $I$ think that is another story, to be mentioned rather than discussed here, for we shall have fully enough to do if we concentrate on uncomplicated tuberculosis.

We are now at a critical time-conservative treatment in open-air hospitals has become well accredited, for its immediate results are known to be good. We must be carcful lest we allow good "results" to become bad " cnd-results." So-called "results" merely represent an interim report in the hospital records. Our main concern, and the true test of our work, is the end-result-the lasting health and activity of the patient, or the reverse. Alan D. Smith and W. H. Watters, writing in the Journal of the American Medical Association for January 21st, 1028, give the following figures:

" 1. Of 208 patients treated for tuberculosis of the hip at the Country Branch of the New York Orthopaedic Dispensary and Hospital from 1904 to 1921, forty-six, or 22 per cent., were found to have wrong diagnoses. We believe that such mistakes are

* Read in opering a dircussion in the Seation of Orthopaedics at the * Read in opening a dircussion in the Seotion of Orthopaedics at
Annual Meeting of the British Medical Association, Manchester, 1929. inevitable unless the diagnosis is established by aspiration and guinea-pig inoculation, or by exploratory operation.

2. 'Thirty-six patients, or 24 per cent. of 150 cases, followed

or three years or more, died, the majority from tuberculosis.

" 3 . Seventy-one cases, or 47 per cent., still were active when last examined.

" 4 . Forty-one cases, 27 per cent., were quiescent with little or no motion and with some degree of deformity.

"5. Only two patients were free from symptoms and had useful range of motion."

There is no reason to suppose that these figures are representative. For "end-results" depend on severad factors which vary in different countries and different clinics. "Find-results" depend partly on (1) the type and (2) the period of treatment in hospital, and partly on the environmental care afterwards. At the Wingfield Orthopaedic Hospital, Oxford, we have been able to take such care of the enxiromment of our patients after ther leave hospitai, and to see them so regulariy, and to admit them again promptly if necessary, that $\dot{I}$ think we ean, in the great najoritr of cases, achieve healing. both of the joint and of the lymphatic tubercmosis. But as regards both phases of the infection we have has failures, and it is from the failures that we bave most to learr.

Now we cannot afford to allow open air and rest to become discredited: they are fundawental needs, and cannot be replaced. Therefore we must learn to mate our end-results come into line with our results. And here we nake contact with our subjert; for surgery has a big part to play in the stabilization of results, Big but limited. It is to discuss that part, its limits and its importance, it, successes, its difficulties, and its failnres, that we are met.

\section{Revin of Surgrcal Tuberculosis.}

With added experience we must again face the question, "When, if ever, is surgical tuberculosis properdy surgical?" But before we begin to answer it, it is well to look squarely at the disease we are fighting and to review critically the parts that can be played by various operative (and non-operative) methods in its treatment.

Now I said in a paper read at the Provincial Meeting of the Tuberculosis Society at Cambridge on April 11th, 1924 :

" Tuberculous disease of a joint or a bone is serious enough but it is a weed with a very deep root; you may pluck the head but the root will not come with it. A bone focus is a proof of established tuberculous infection of the bedy; but even this is not an, for the new focus is tangible eridence that the invasion of the body is advancing."

I feel now that the metaphor was partially misleading, for I have become convinced that the seeds of dissemination lie in the root of the disease and not in its flower. No doubt then, as now, I was preaching to the converted, but it is well to reassert this basic truth over and over again until the whole profession absorbs it. The family doctor knows the true facts, the orthopaedic surgeon is learning them, but in the general hospitals, with the relatively early discharge of patients which is necessary, the slow evolution of surgical tuberculosis cannot be watched.

On the other hand, the experience of surgical tubereulosis one grts on the staff of a hospital such as the Wingfield has ail the makings of a scientific experiment on a large scale; for one sees the cases in our scattered out-patient departments before their hospitai period, and lives surrounded by them, and in touch with them even after their discharge. It is a living and lasting experiment, and one learns more and more as the years pass. The experiment is characterized not only by the large number of cases, but by their unlimited variety in age, type, and environment. I am being led to a conception of the disease which has points that may be new and are, I think, raluable. Certainly they concern intimately to-day's subject.

In the second part of this paper I hope to give sume of the findings of the experiment. For my present purpose I must anticipate them and pick out one striking point. In most of the patients in whom new lesions occurred, not as a result of the originai bacillary shower, but at a later stage-that is, during or after hospital treatment-the joint lesion has at the time of the new development been removed or arrested, and in the latter there have been no signs of activity or reactivity in the joint lesion proceding or at the time of the development of the new lesion. This is a clear indication that the bacillaemio 